\title{
Aspects regarding the consequences of chemical contamination of food
}

\author{
Daniela Cîrţînă ${ }^{1}$, Maria Modoran ${ }^{2}$ \\ 1 “Constantin Brâncusi” University of Tg-Jiu, Faculty of Medical and Behavioral Sciences, No. \\ 4, Tineretului St., Tg-Jiu, Romania \\ 2"Constantin Brâncusi” University of Tg-Jiu, Department for International Relations and \\ Community Programmes, No. 4, Tineretului St., Tg-Jiu, Romania \\ E-mail: danielacirtina@gmail.com
}

\begin{abstract}
The present paper aims to present some interest aspects of the use of adjuvant and contaminating chemicals on food quality and implicitly on the human body. The intake of harmful substances through food has a significant influence as an ecological factor on humans, producing food imbalances and even the appearance of diseases that influence health.
\end{abstract}

Keywords: food, chemical contaminants, adjuvants

\section{Introduction}

Chemical treatment and pollution of food represents currently a particular interest in terms of food quality control and the consequences that the aforementioned processes have on the human body. Changes and interventions made in the technologies for obtaining, preserving, marketing food have more or less justified consequences, which have often led to imperative decisions or behavior on the part of the responsible bodies for the public health safety. From the category of components of the environment that influence health, food has a major importance. The quality of food has, in fact, a significant impact from an ecological point of view, being in a position competing with food imbalances due to its excess or deficiency. [1]

Over time, there have been a number of causes that have underpinned food conditioning by humans, causes determined by increasingly sophisticated subjective or objective consumer claims that have led to the diversification and accelerated growth in the number of assortments, causes due to the growing needs of a growing population or causes determined by the need to ensure an additional stock in order to supply rationally and efficiently the large urban agglomerations. Finding viable solutions for the production of foods that are enriched, concentrated or of major interest under certain conditions (dietary, used in certain physiological periods of childhood, pregnancy, for certain types of activities etc.) is also another cause of conditioning food. The need for food safety and food safety conditions has always been a priority objectives for those who are working in the field of food quality control and assurance. All these causes and needs have forced the emergence of a series of new manufacturing technologies, which often involve, although not necessarily, certain chemical treatments. Often, food undergoes purely chemical treatments or is simply contaminated, like the rest of the components of the environment, in a way that is difficult to avoid or irresponsible. [2,3]

A series of synthetic chemical compounds, without nutritional value, reach the food in various ways, in an increasing number, through the chemical treatments to which the food is subjected, frequently 
burdened by the probability of a harmful intake appearance. The scale of the processes of chemical treatment and pollution of food has reached such high levels, and the particularities of these processes are so obvious that it is now important to investigate possible harmful effects and potential toxicological risks that some foods can manifest it. [4]

\section{The main causes and consequences of chemical pollution of food}

The causes of chemical pollution of food are represented by the complexity and diversity of chemicals added to food deliberately or by illegal ways that raise serious public health problems. The action of these compounds can have effects on food and implicitly on the human body by manifesting various disorders, depending on the substances nature found in the food. The evaluation process of the potential risk to humans is a difficult one and necessarily requires constantly updated legislation at an appropriate level of knowledge and development.

A classification of the main substances that reach the food implies the existence of two main categories, namely: adjuvants or food additives and contaminants or pollutants themselves.

The legislative implications of the society for the possible existence of these substances in food, determinates that the difference between these two categories be made in relation to their usefulness, justification of their existence or toxicity. [5,6]

Food adjuvants are a category of chemicals intentionally added to food for various purposes, their use is either a technological necessity, helping to improve the yield, thus avoiding losses and with a protection effect on the nutrients during the preparation process etc., or as a practical necessity (indispensable stabilizers or preservatives for the storage process). Also, their use can be accepted as a necessity of some modifications, improvements of the treated food, from an organoleptic point of view.

The addition of adjuvants is generally preceded by a study regarding their technological necessity and safety. Due to the structural diversity characteristic of these substances and the fact that a number of difficulties arise in the toxicological evaluation process, their admissible number is in a continuous dynamic influenced by the information on the possible direct or indirect harmful action that adjuvants may have. The amount of such substances allowed to be found in food is regulated by the legislation in each country, as well as the nature of the food in which they can be added. [7,8]

The chemical structure of the adjuvants used in the food industry is a complex one, the number of these substances is high and constantly growing, and a coherent classification of them takes into account the purpose for which they are used. Thus, food adjuvants are divided into preservatives substances: substances that oppose biological changes (antiseptics, antibiotics, antigerminatives), substances that oppose chemical changes (antioxidants) and substances that oppose physical changes (anti-caking, emulsifiers, binders etc.), respectively organoleptic (or ameliorative) substances: dyes and bleaches, flavorings and flavor enhancers and synthetic sweeteners. The contaminants (food pollutants) are found in a virtually unlimited number, which effectively depends on the possibilities of contamination or pollution under the influence of various environmental factors. The diversity of the chemical structure of these substances in relation to that of the adjuvants is bigger. [6-8]

The qualitative and quantitative quantification of contaminants in food is strictly limited by food safety and security standards. The acceptance of their presence is allowed within certain limits, rigorously established by the current legislation which underlies the substantiation of food manufacturing technology and the prevention of its contamination. If the existence of contaminants becomes harmful to the human body, they cause the inability of the food and its exclusion from consumption.

Among the sources of food chemical contaminants can be mentioned: chemical treatments in agriculture and animal husbandry (pesticides, biostimulators, fertilizers), excessive and traumatic physical treatments (formation of toxic polymers, degradation compounds), use of impure raw materials, solvents etc., contamination in packaging, contamination in the unpacking or handling process, contamination with toxic compounds resulting from biological processes (amines, mycotoxins), harmful compounds concentrated in the plant or animal tissues from the water, air, soil (carcinogenic hydrocarbons, metals, toxic metalloids) or pre-existing harmful compounds in some products. [8,9] 
The action of chemicals on food assumes that adjuvants or contaminants and especially technological processes often have secondary actions on food. As a result of the heat treatments to which foods are subjected, toxic compounds, such as aldehydes, ketones or polymers with toxic action, can appear in food fats. Harmful compounds can also be formed through the reaction of some adjuvants and nutrients in food. The formation of sulfoximine in flours treated with nitrogen trichloride, the formation of nitrosamines in the presence of excess nitrates or the formation of ethylene chlorohydrin from ethylene oxide, used as a pesticide can be considered that type of examples. The nutrients destruction, namely inactivation of vitamins $\mathrm{C}, \mathrm{B}_{1}$, heat treatments, inactivation of vitamins $\mathrm{A}, \mathrm{E}$ and $\mathrm{B}_{2}$, due to oxidation, loss of water-soluble vitamins or mineral salts by washing, inactivation of the protein amino acids as a result of heat treatments or treatments with adjuvants such as carbon dioxide, bromates, ethylene oxide, methyl bromide, hydrogen peroxide etc., are also forms of the action of technological processes on food quality. [9-11]

The influence of food contamination with foreign substances added or introduced illegally in the human body is materialized in direct or indirect actions. The toxic potential of foreign substances in food can only be assessed to the extent that these substances cause obvious manifestations or endanger the life of the consumer.

A number of chemicals present in food may not be harmful themselves, but may facilitate the toxic action of others or may simply not be tolerated by the human body in a certain form of processing. Thus, examples can be a series of emulsifiers used in confectionery and bakery, or in the fat industry. Another example in which food can undergo changes caused by technology is modified starches, mechanically or enzymatically, in the sense of reducing the polysaccharide granule and obtaining improved organoleptic products with an increased digestive utilization coefficient for children's nutrition. In the case of these products, a certain harmful action was highlighted, due to the absorption without hydrolysis of the too finely divided polysaccharide, which causes allergic manifestations etc.

The consequences of the use of contaminants can have for humans, an influence that can manifest itself from a simple action of digestive or metabolic interference, to oncogenesis. Thus, we can mention the local anti-enzymatic action of food preservatives that act by mechanisms similar to those that make them active against microorganisms. [10,11]

They exert inhibitory or destructive influences on the enzymatic system of the digestive tract and cause changes in the digestive utilization coefficient (preservatives, antiseptics, salicylic acid, benzoic acid etc.). Other forms of action are: irritating or keratinizing action on the digestive mucosa (salicylic acid, phenol, formic aldehyde, etc.), the organotropic action determined by a certain preference of chemicals for some tissues (tissues rich in lipids, bones etc.), or the possibility of the organs to metabolize, detoxify or excrete these substances as well as the allergenic action. The mutagenic, teratogenic, oncogenic actions explain the increased percentage of neoplasms caused by pollutants that reach the body through food. The explanation consists in the great diversity of carcinogenic compounds that can appear in food or coming from the intentional addition of substances with malignant, mutagenic, teratogenic potential. Another example is the possibility of the formation of carcinogenic compounds produced by a series of common molds, which populate food (aflatoxins). [10-12]

\section{Conclusions}

Although it has long been considered a secondary problem, the action of chemicals on food must be taken into account, which either results in a decrease in nutritional value or possible harm to the human body. Adjuvants or contaminants and technological processes often have side effects on food. The thermal, chemical, physical treatments to which the food is subjected, can generate toxic, harmful compounds, formed, in part, by the reaction between some adjuvants and the nutritional components of the food. The influence of foreign substances in food, added or introduced illegally is materialized in direct or indirect actions on the human body. A number of chemicals present in food may not be harmful themselves, but may facilitate the toxic action of others or may not be tolerated by the human body in some form of processing. The use of contaminants can have for humans, an influence that can manifest itself from a simple action of digestive or metabolic interference, to oncogenesis. Harmful effects can 
be aggravated by the high incidence of contamination, by prolonged preservation of the harmful agent and the possibility of coexistence of co-carcinogenic factors, accessible to the consumer throughout life. The possibility of contaminating food with harmful, carcinogenic substances, which cause serious biological disorders, is higher than for other components of the environment.

\section{References}

[1] Banu, C., Nour, V., Vizireanu, C., Mustaţă, Gr., Răsmeriţă, D., Rubţov, S., Quality and control food quality, AGIR Publ. House, Bucureşti, 2002.

[2] Mihele, D., Physico-chemical analysis and control of food, Multi Press International Publ. House, Bucuresti, 2003.

[3] Ciobanu, D., Ciobanu, R., Food chemistry. Analytical investments, Tehnica Info Publ. House, Chişinău, 2002.

[4] Dumitrescu, H., Milu, C., Dumitrescu, C.D., Ciubotaru-Bordeianu, A., Albulescu, V., Physicochemical control of food, Medicala Publishing House, Bucuresti, 1997.

[5] Tofana, M., Food additives and conservability, AcademicPres Publishing House, Cluj-Napoca, 2003.

[6] Banu, C., Preda, N., Vasu, S., Food and their safety, Tehnica Publishing House, Bucuresti, 1982.

[7] Cîrțînă, D., Traistă E., Traistă C., Danciu C., Environmental sanitary chemistry, Academica Brâncuși Publishing House, Tg-Jiu, 2017.

[8] Barnea, M., Calciu, Al., Human ecology, Medicala Publishing House, Bucuresti, 1979.

[9] Bulancea, M., Rapeanu, G., Authentication and identification of food counterfeits, Didactica and Pedagogica Publ. House, Bucuresti, 2009.

[10] Simion, C., Albu, H., Simion, A., Food quality and control, Printech Publ. House, Bucuresti, 2007.

[11] Mănescu S., Cucu M., Diaconescu M. L., Environmental health chemistry, Medicală Publishing House, Bucureşti, 1994.

[12] Popa, G., Dumitrache, S., Segal, B., Segal, R., Apostol, C., Teodoru, V., Food toxicology, Academiei Publ. House, București, 1986. 